$\S=-1$

\title{
Lift distribution of washout twist morphing MAV wing
}

\author{
N. I. Ismail*, H. Yusoff**, Hazim Sharudin, Arif Pahmi, H. Hafiz, Mahadzir M. M. \\ Faculty of Mechanical Engineering, Universiti Teknologi Mara, Kampus Pulau Pinang, Permatang Pauh, Pulau Pinang, Malaysia \\ *Corresponding author E-mail: iswadi558@ppinang.uitm.edu.my
}

\begin{abstract}
Micro Air Vehicle, or also commonly known as MAV, is a miniature aircraft that has been gaining interest in the industry. MAV is defined as a flying platform with $15 \mathrm{~cm}$ wingspan and operates at a speed of around $10 \mathrm{~m} / \mathrm{s}$. Recently, MAV has been exposed with the latest development and link towards the biologically-inspired designs such as morphing wing. Twist morphing wing is one of the latest MAV wing design developments. The application of Twist Morphing (TM) on MAV wing has been previously known to produce better aerodynamic performance. Previous study in washin TM wing has shown a promising possibility of generating higher lift force. Despite the benevolent performance exhibited by the washin TM wing, the lift distribution for the washout type of TM MAV is relatively unknown and still open to be explored. This is probably due to the lack of experimental test rig to produce the washout twist morphing motion on the MAV wing. Therefore, this research aims to produce a special test rig for washout TM wing that is compatible for wind tunnel experimental testing. By using the special test rig, the experimental investigation on the lift performance of washout TM MAV wing can be done. Based on the wing deformation results, it clearly shows that the proposed test rig is capable to produce up to $19.5 \mathrm{~mm}$ tip deflection at the morphing point, which is also resulting in a significant morphing motion. Higher morphing force induces larger morphing motion. Based on the lift distribution results, they show that the morphing motion has significantly affected the overall lift distribution on the MAV wing. The morphing motion on TM wing has produced at least $17.6 \%$ and $5.33 \%$ lower $C_{L}$ and $C_{L m a x}$ magnitude, respectively, with the membrane wing especially at the pre-stall region. However, the TM wing is still able to maintain the stall angle similar to the baseline wing at $\alpha_{\text {stall }}=31^{\circ}$. By maintaining high $\alpha_{\text {stall }}$ value with lower $C_{L}$ and $C_{L m a x}$ magnitude, TM wing produces more agility for the MAV maneuverability that will be useful for indoor mission or obstacle avoidance flight.
\end{abstract}

Keywords: micro air vehicle; morphing; twist morphing; washout morphing; Zimmerman wing

\section{Introduction}

Micro Air Vehicles or also generally known as MAVs are a miniaturized aircraft that have been aimed to assist in situations where the use of larger vehicles are restricted. Its small size has attracted huge interest amongst military organizations as well as civilians. The common MAV measures to a size of approximately $15 \mathrm{~cm}$ and operates at a speed of around $10 \mathrm{~m} / \mathrm{s}$ [1]. With limitless potential, MAVs can be adapted to numerous applications such as surveillance and reconnaissance.

Enormous amount of research has been conducted to comprehend the flying attitude of aircraft by adopting natural flyers wing mobility on the MAV application. This method is known as biologically-inspired or biomimetic design [2], which is an area of study related to mimicking the natural biological systems. Biomimetic design incorporates feasible biological science (with reverse engineering concept) of a certain mechanism into a technology field. Flapping [2] and morphing [3] wing concepts are some examples of biologically-inspired designs, which have already been successfully implemented on MAV platform by previous researchers [4]. Natural flyers have fully manipulated their multi-hinged skeleton, flexible skin and their naturally distributed compliance wings for flight manoeuvres. Multi-hinged bones, elastic skin and also natural compliance wing are significant compliance elements that are found on the wing of biological flyers [5]. The stiffness and flexibility structure of natural flyers are naturally utilized to ensure the continuity of wing mobility and optimize the surrounding airflow.
These unique features are fundamentally parallel to the morphing of MAV wing concept, and the features contribute to less complex structure and provide smooth continuity shape changes. However, mimicking the natural flyer agility and flight performance has led to a complex study of the mechanism, fluid-structure interactions (FSI) [6], aeroelasticity, flight dynamics [7] and control systems. Despite the maturity in computational fluid dynamics (CFD), the aerodynamics and structural attitudes of natural flyers are still not fully understood and are difficult to implement in artificial flyers such as MAV [8]. More efforts from the aerospace researchers are anticipated to expand the aerodynamics understanding [9] and its relationship to the wing structural mobility. Hence, in the current research, the investigation on biomimetic wing design is continued in order to comprehend morphing wing structural behaviour and its relationship to the overall aerodynamic performance. The study is focused on a biomimetic MAV wing design with twist morphing capability, known as twist morphing (TM) MAV wing.

Morphing is defined as the ability of an aircraft's wing to change its shape during flight to improve the overall flight performance. Morphing is also known as a biomimetic wing design that provides a smooth and continuous wing shape changes through the feature of wing flexibility. Specifically, the lift distribution across the wing, which has a direct effect on drag and the power needed for ascending, is likely to be affected by the morphing action. A MAV that morphs would have experienced a reduction in drag since the control surface is continuous rather than discreet, which typically leads to a longer flight range. Morphing wing is a new generation of wing mobility adopted in MAV flight and can nor- 
mally be classified accordingly to the outcome of shape parameters. There are three main categories of morphing wings known as in-plane alternation, out-of-plane transformation and airfoil profile adjustment.

The TM wing concept is a technique whereby any part of the wing is deflected at an angle of any direction to achieve a better aerodynamics capability. TM wing can be divided into two main categories: washin and washout TM wing. The difference between these washin and washout wing conditions is shown in Figure 1. Theoretically, the application of washin TM has shown significant improvements in the flight agility and lift-to-drag ratio. The previous study in washin TM wing has shown promising possibility of generating higher lift force.

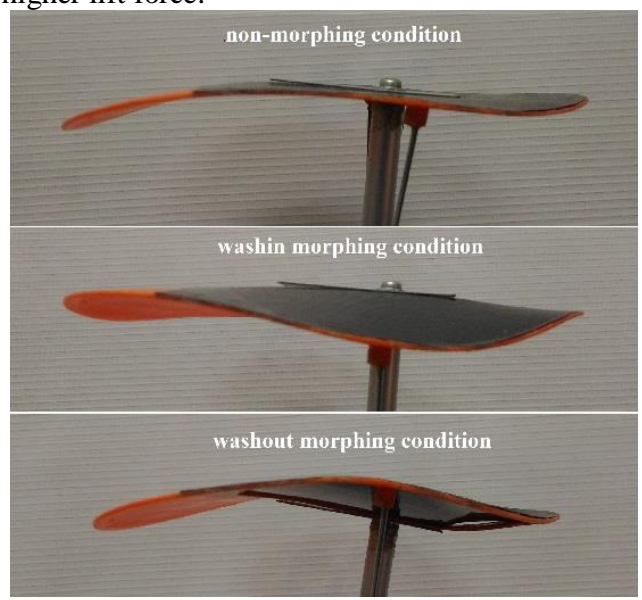

Fig. 1: Washin and washout morphing wing

Despite the benevolent performance exhibited by the washin TM wing, lift distribution for washout type of TM MAV is relatively unknown and still open to be explored. This is probably due to the lack of experimental test rig to produce the washout twist morphing motion on MAV wing. Therefore, this research aims to produce a special test rig for washout morphing motion that is suitable for wind tunnel experimental testing. By using the special test rig, experimental investigation on the lift performance of washout TM MAV wing can be better continued. In this works, an experimental washout TM wing test rig has been developed for the wind tunnel testing purpose. The test rig is able to produce a significant amount of wing tip deflection at the morphing point, which is used to indicate the level of the morphing motion. In order to elucidate lift performance of the washout TM wing, four variants of washout configurations (known as TM0N, TM1N, TM3N and TM5N) are used to test in a standard wind tunnel procedure.

\section{Washout TM wing model}

Prior to the wing development process, the washout TM wing has been developed based on a Zimmerman wing shape that is aligned with the previous washin TM wing study. The washout TM wing has an aspect ratio of 1.25 and other wing specifications for washout TM wings are given in Table 1 . The table shows that the difference between each of the washout TM wings is only the morphing force component level applied to induce the washout motion on each wing. TM0N is actually the baseline wing that also known as membrane wing. It is used as a reference and comparison to the higher morphing level.

The washout TM wing skeleton (as illustrated in Figure 2) is built based on the membrane reinforced MAV wing with a Zimmerman shape [10]. The washout TM wing skeleton is fabricated using the Zortrax M200 3D printer and ABS plastic material is used for the wing skeleton. This material has been selected due to its strength and flexibility, which is also conducive to washout TM morphing study. ABS plastic also possesses good machinability and hightemperature resistance that is very conducive for repeatability and real-flight-test in future works. To ensure the wing is satisfactorily flexible, the $2 \mathrm{~mm}$ wing skeleton is attached with a silicone membrane skin layer as shown in Figure 3. This is to maintain the wing flexibility as membrane wing and it is also conducive for uncomplicated morphing actuation.

Table 1: Washout TM wing specifications

\begin{tabular}{|c|c|c|c|c|}
\hline & TM 5N & TM 3N & TM 1N & TM 0N \\
\hline Wingspan, b & $150 \mathrm{~mm}$ & $150 \mathrm{~mm}$ & $150 \mathrm{~mm}$ & $150 \mathrm{~mm}$ \\
\hline Root chord, c & $150 \mathrm{~mm}$ & $150 \mathrm{~mm}$ & $150 \mathrm{~mm}$ & $150 \mathrm{~mm}$ \\
\hline $\begin{array}{c}\text { Aspect ratio, } \\
\text { A }\end{array}$ & 1.25 & 1.25 & 1.25 & 1.25 \\
\hline $\begin{array}{c}\text { Maximum } \\
\text { camber at the } \\
\text { root }\end{array}$ & $\begin{array}{c}6.7 \% \text { of } \mathrm{c} \\
(\text { at } \mathrm{x} / \mathrm{c}= \\
0.3)\end{array}$ & $\begin{array}{c}6.7 \% \text { of } \mathrm{c} \\
(\text { at } \mathrm{x} / \mathrm{c}= \\
0.3)\end{array}$ & $\begin{array}{c}6.7 \% \text { of } c \\
(\text { at } x / c= \\
0.3)\end{array}$ & $\begin{array}{c}6.7 \% \text { of } c \\
(\text { at } x / c= \\
0.3)\end{array}$ \\
\hline $\begin{array}{l}\text { Maximum } \\
\text { reflex at the } \\
\text { root }\end{array}$ & $\begin{array}{c}1.4 \% \text { of } \mathrm{c} \\
(\text { at } \mathrm{x} / \mathrm{c}= \\
0.86)\end{array}$ & $\begin{array}{c}1.4 \% \text { of } \mathrm{c} \\
(\text { at } \mathrm{x} / \mathrm{c}= \\
0.86)\end{array}$ & $\begin{array}{c}1.4 \% \text { of } \mathrm{c} \\
(\text { at } \mathrm{x} / \mathrm{c}= \\
0.86)\end{array}$ & $\begin{array}{c}1.4 \% \text { of } \mathrm{c} \\
(\text { at } \mathrm{x} / \mathrm{c}= \\
0.86)\end{array}$ \\
\hline $\begin{array}{l}\text { Built-in } \\
\text { geometric } \\
\text { twist }\end{array}$ & $0.55^{\circ}$ & $0.55^{\circ}$ & $0.55^{\circ}$ & $0.55^{\circ}$ \\
\hline $\begin{array}{c}\text { Force } \\
\text { component }\end{array}$ & $\begin{array}{c}\text { Included } \\
\mathrm{F}=5 \mathrm{~N}\end{array}$ & $\begin{array}{c}\text { Included } \\
\mathrm{F}=3 \mathrm{~N}\end{array}$ & $\begin{array}{c}\text { Included } \\
\mathrm{F}=1 \mathrm{~N}\end{array}$ & $\begin{array}{c}\text { Excluded } \\
\mathrm{F}=0 \mathrm{~N}\end{array}$ \\
\hline $\begin{array}{l}\text { Membrane } \\
\text { skin } \\
\text { component }\end{array}$ & Included & Included & Included & Included \\
\hline $\begin{array}{l}\text { Approximate } \\
\text { membrane } \\
\text { skin location }\end{array}$ & $\begin{array}{c}0.34 \leq \mathrm{x} / \mathrm{c} \\
\leq 0.9 \\
0.10 \leq 2 \mathrm{z} / \mathrm{b} \\
\leq 0.83\end{array}$ & $\begin{array}{c}0.34 \leq \mathrm{x} / \mathrm{c} \\
\leq 0.9 \\
0.10 \leq 2 \mathrm{z} / \mathrm{b} \\
\leq 0.83\end{array}$ & $\begin{array}{c}0.34 \leq \mathrm{x} / \mathrm{c} \\
\leq 0.9 \\
0.10 \leq 2 \mathrm{z} / \mathrm{b} \\
\leq 0.83\end{array}$ & $\begin{array}{c}0.34 \leq \mathrm{x} / \mathrm{c} \\
\leq 0.9 \\
0.10 \leq 2 \mathrm{z} / \mathrm{b} \\
\leq 0.83\end{array}$ \\
\hline
\end{tabular}

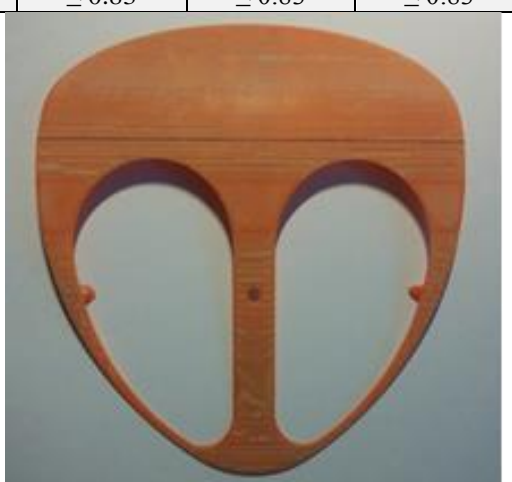

Fig. 2: Washout TM wing skeleton

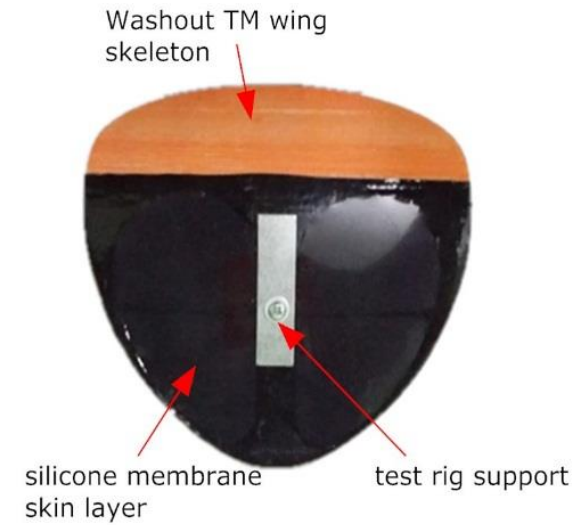

Fig. 3: Wing skeleton with a silicone membrane skin layer

\section{The experimental setup}

\subsection{Washout twist morphing test rig}

A special test rig has been developed to ensure that the wing can be morphed easily and it is also compatible with the wind tunnel facility. The test rig comprises the horizontal and vertical rod arms as shown in Figure 4. The two distinguished dimension rods look like an L-shape balancing arm and fastened to the wing. The arm is stiff and it is able to hold the TM wing in place during the wind tunnel experiment. The vertical arm clamps the wing and the hori- 
zontal arm is attached to a balancing unit. The wing is mounted parallel to the slider rod to ease the morphing actuators by extruding similar amount of force on the wing tip. The slider rod movement affects the TM wing by displacing the wing tips at positive $\mathrm{y}$-axis direction simultaneously.

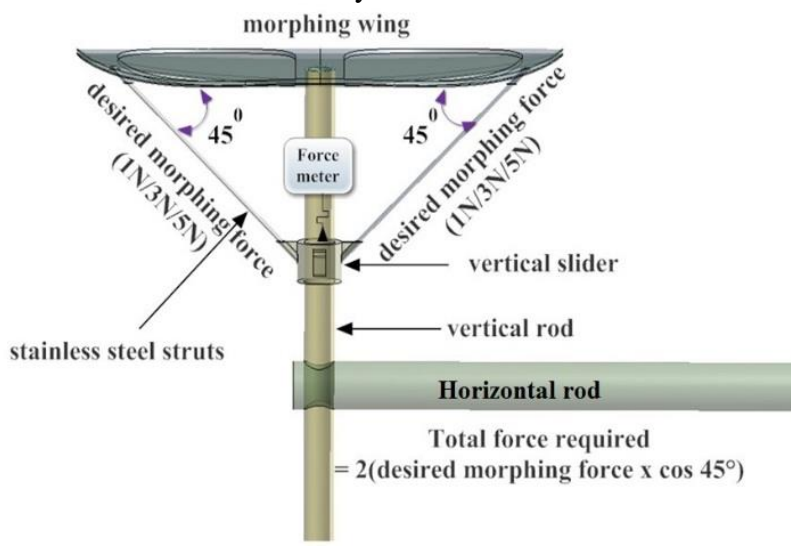

Fig. 4: Test rig designed for washout TM morphing

The morphing forces are measured by using a force meter and the setup is based on the quasi-static condition. Morphing force measurements and implementations have been carried out outside of the test section prior to a wind tunnel run in order to avoid having the wing model responding to any unwanted external loads. This is also to avoid the strain gauge sensor failure since it cannot be exposed to susceptible interference, hysteresis, creep and temperature drift. The detailed steps to set the level of washout TM wing motion are shown in Figure 5.

The washout morphing motion is accomplished using a set of two thin, stainless steel struts, affixed between the vertical slider and the predetermined morphing points at wing tips similar to previous works [3]. As the vertical slider adjusts its position along the vertical rod, both struts produce an axial force that is appropriate for morphing. Actuating this vertical slider forces the wing to undergo a wash-out twisting displacement (y-axis direction). The extent and shape of the morphing can be adjusted by changing the level of axial force imposed on the vertical slider. Thus, the control of wing twist deformation is largely a function of the vertical slider position along the vertical rod (minor effects from the response of the airloads are negligible). The magnitude of the twist deformation is the largest at the morphing point and, although the morphing point is highly localized around the wing tip, the wing surface distributes the twist deformation over the entire wing.

\subsection{Wind tunnel facility}

The wind tunnel facility used in this experiment is an open circuit subsonic wind tunnel located at School of Aerospace Engineering, Engineering Campus, Universiti Sains Malaysia. The wind tunnel is about $3 \mathrm{~m}$ long with a hollow settling chamber and a contraction ratio of $3: 1$. The wind tunnel has a test section with a dimension of $300 \mathrm{~mm}$ (width) x $300 \mathrm{~mm}$ (length) x $600 \mathrm{~mm}$ (height). The wind tunnel turbulence intensity is measured at $5 \%$ with $5.6 \%$ of wake blockage. The experimental equipment for the wind tunnel test is comprised of force measuring system and data acquisition (DAQ) device. The force measurement equipment is supported by a personal computer, which is equipped with data acquisition software. The positioning and setup washout TM wing in the wind tunnel facility is shown in Figure 6.
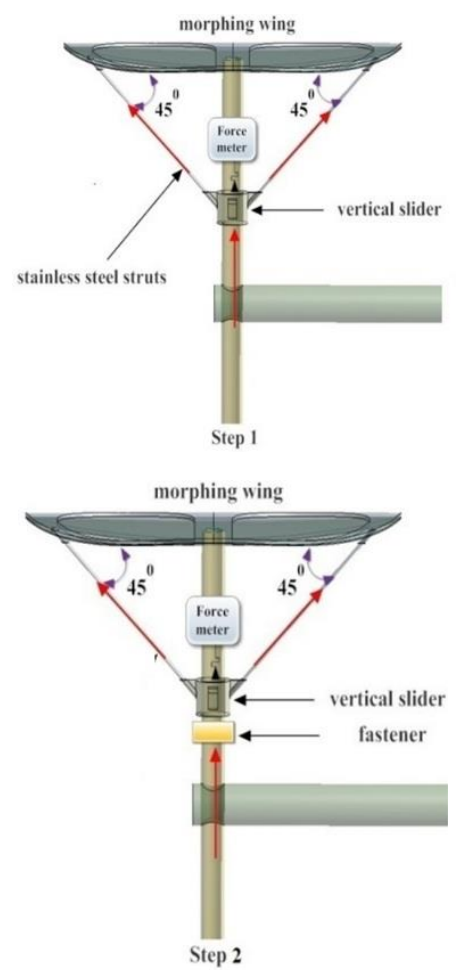

morphing wing

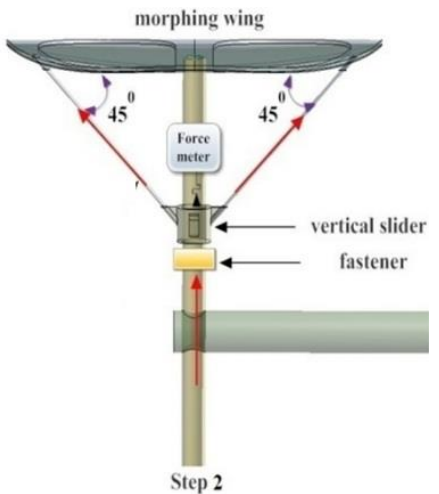

Fig. 5: Step 1 to 3 for washout TM wing setup

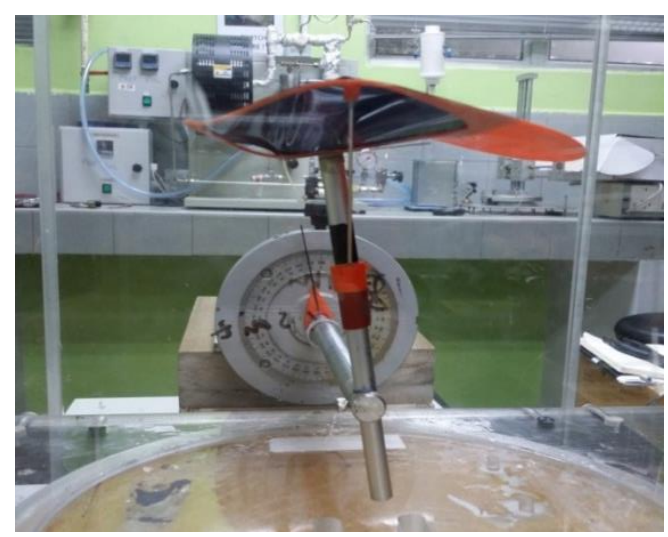

Fig. 6: Washout TM wing setup

A series of wind tunnel experiments has been conducted to analyse the lift performances of the TM MAV wing. The experiments are designed to measure the lift forces exerted by the wing during flight. The force measuring system (balancing unit) is made up of a Deltalab strain gauge sensor used to measure lift with high precision. The wind tunnel velocity is kept constant at $9.7 \mathrm{~m} / \mathrm{s}(R e$ of $100,000)$ to emulate the maximum speed of MAV class. The angle of attack setting is varied between $-10^{\circ}$ to $35^{\circ}$, which is within the MAV operating angle range. The wind tunnel experimental procedure is summarized in Figure 7. 


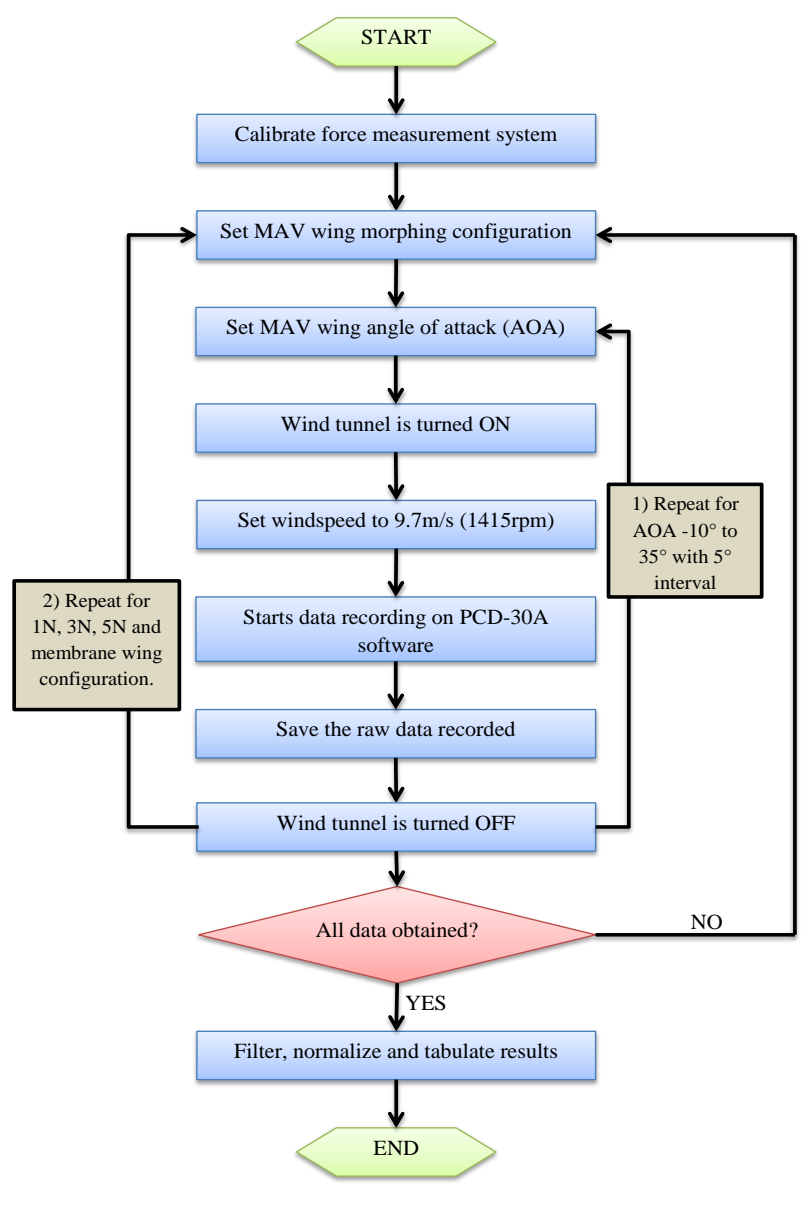

Fig. 7: The wind tunnel experimental procedure.

\section{Results and discussion}

\subsection{The morphing deformation results}

To ensure that the morphing deformation is achieved for each TM wing, the wing tip deflection at morphing point location has been considered for wing deformation analysis. The results of morphing deformation for each wing are presented in Figure 8. Each wing produces almost a similar pattern of wing deformation. However, the deformation is noticeably varied along the wing laterally. The highest level of deformation wing is found at the wing tip, which slowly reduces towards the wing centre location. The result shows that the higher morphing force induces larger wing tip deflection and this is used to indicate a larger morphing motion. The TM5N wing clearly induces the largest wing tip deflection (at $19.5 \mathrm{~mm}$ ), which the largest morphing motion among the wings. Both TM3N and TM1N wing have produced a moderate wing tip deflection at $11.7 \mathrm{~mm}$ and $3.15 \mathrm{~mm}$, respectively. Nevertheless, the membrane wing induces the lowest wing tip deflection at $0 \mathrm{~mm}$. This result is expected since the membrane wing does not have an external load force on the wing tip and the configuration is only used for baseline wing indicator (non-morphing configuration). Based on wing tip deflection results, one can conclude that higher morphing force induces larger wing tip deflection.
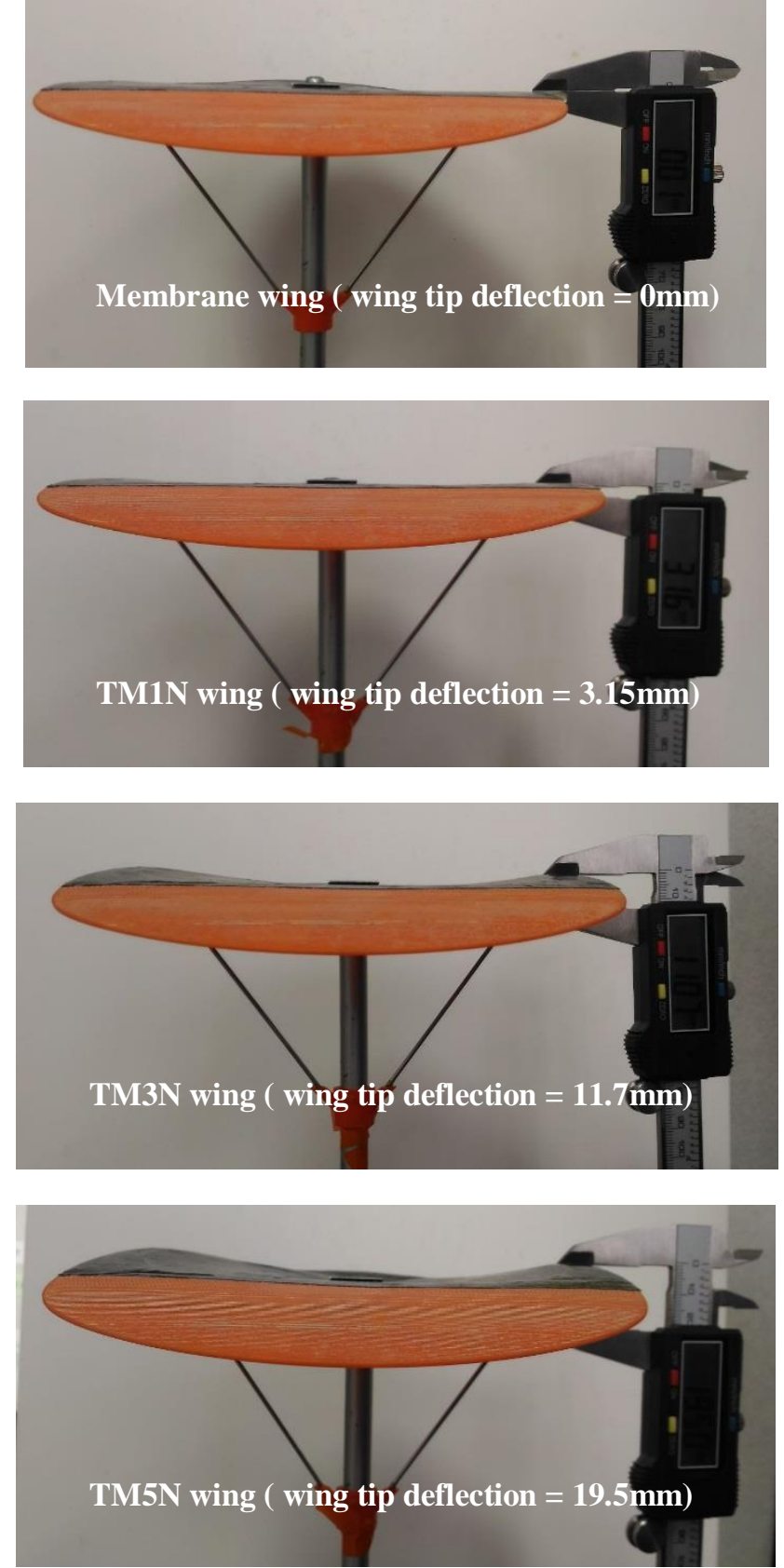

Fig. 8: The morphing deformation at the wing tip for each wing

\subsection{The lift distribution results $\left(C_{L}\right)$}

The plot in Figure 9 presents $C_{L}$ performances of all wing configurations based on the wind tunnel experiment results. The results show that every wing configuration has a distinct $\mathrm{C}_{\mathrm{L}}$ distribution curve across the angle of attack (AoA) measured. However, the $C_{L}$ curve trend is almost similar to every wing throughout the AoA range. $C_{L}$ values for each wing increase proportionally with AoA towards its peak magnitude at the maximum lift coefficient $\left(\mathrm{C}_{\mathrm{Lmax}}\right)$ and stall angle $\left(\mathrm{AoA}_{\text {stall }}\right)$ before it slowly decreases at the post-stall region $\left(>A_{o} A_{\text {stall }}\right)$. Based on Figure 9 , the membrane wing clearly demonstrates the highest $\mathrm{C}_{\mathrm{L}}$ magnitude throughout the pre-stall region $\left(<\mathrm{Ao} \mathrm{A}_{\text {stall }}\right)$. Detailed analysis at $\mathrm{AoA}=10^{\circ}$ reveals that the membrane wing produces $C_{L}=1.780$, which is $17.6 \%$ higher than TM1N wing with $C_{L}=1.467$. TM3N wing produces $C_{L}=1.066$, which is $40.4 \%$ lower than the membrane wing and TM5N wing has significantly the least $C_{L}$ value among the wings at $C_{L}=0.511$. This value is about $71.3 \%$ lower than what the membrane wing produced. 


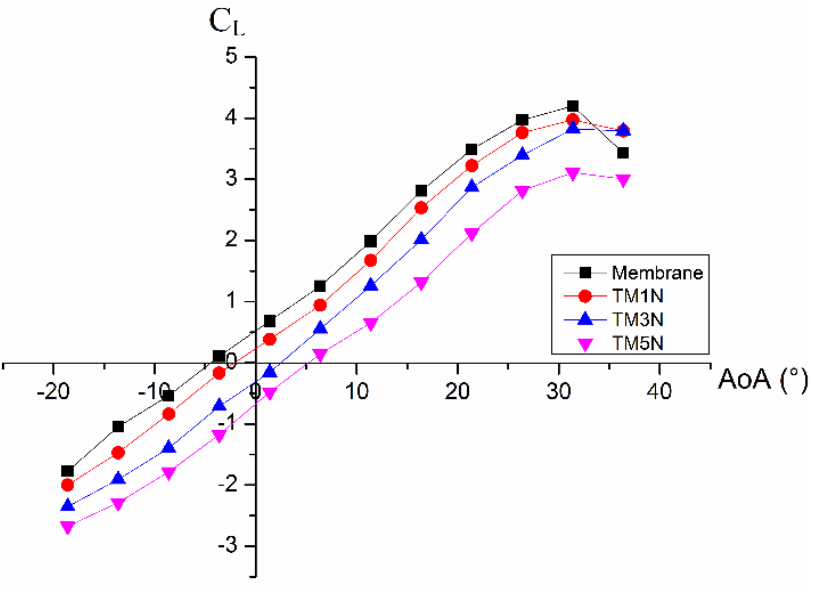

Fig. 9: $C_{L}$ performances of all wing

Based on the initial structural investigation, the washout morphing motion on the TM wing has induced a slight downward nose deflection at the front part of the wing as depicted in Figure 10. The downward nose deflection decreases the magnitude of local angle of attack, especially near the wing tip area, and this in turn reduces the overall lift distribution over TM wing.

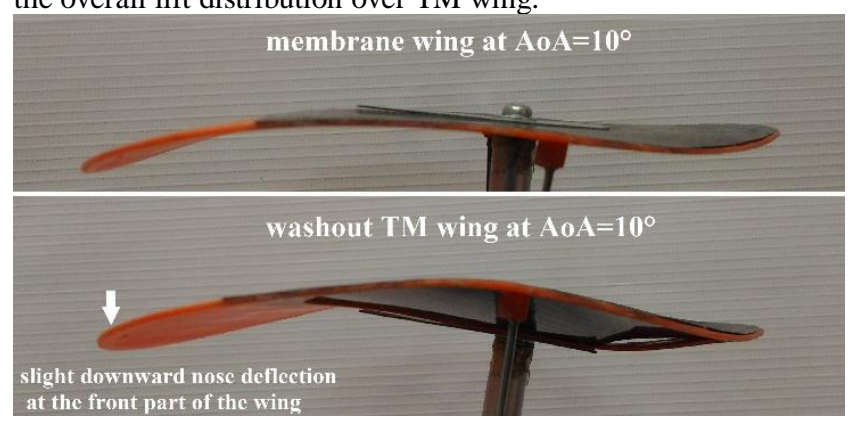

Fig. 10: Downward nose deflection at the front part of TM wing

Extensive analysis is also conducted at $\mathrm{AoA}=20^{\circ}$ and the results also show a similar trend as for AoA $=10^{\circ}$. Membrane wing consistently produces the highest $\mathrm{C}_{\mathrm{L}}$ value among the wings with $\mathrm{C}_{\mathrm{L}}$ $=3.299$. This value is $8.2 \%$ higher than what the TM1N produces $\left(\mathrm{C}_{\mathrm{L}}=3.031\right)$. TM3N and TM5N wing also still produce lower $\mathrm{C}_{\mathrm{L}}$ magnitude compared to the membrane wing with $\mathrm{C}_{\mathrm{L}}==2.628$ and $\mathrm{C}_{\mathrm{L}}=1.893$, respectively. These magnitudes are about $20.3 \%$ and $42.6 \%$ lower than what the membrane wing produces, respectively. Thus based on these analyses, one can conclude that the washout morphing motion induced on each of the TM wings has significantly reduces their lift generation. The higher morphing force that is producing larger morphing motion has significantly affected the overall $C_{L}$ magnitude on the wing. The downward nose deflection has become more visible at higher morphing force, which subsequently decreases the local angle of attack and the overall lift distribution over TM wing.

$\mathrm{C}_{\mathrm{L}}$ curve for each wing increases almost linearly with AoA until it reaches its maximum value $\left(\mathrm{C}_{\mathrm{Lmax}}\right)$. The $\mathrm{C}_{\mathrm{Lmax}}$ magnitude can be found at the peak of $C_{L}$ curve. Based on the detailed $C_{L \max }$ results, it shows that the membrane wing produces the highest $\mathrm{C}_{\mathrm{Lmax}}$ magnitude with $\mathrm{C}_{\mathrm{Lmax}}=4.196$. This magnitude is about $5.33 \%$ higher than what the TM1N wing produces $\left(\mathrm{C}_{\mathrm{Lmax}}=3.973\right)$. TM3N and TM5N wing produce $\mathrm{C}_{\mathrm{Lmax}}$ of 3.824 and 3.110 , respectively. This magnitude is about $8.9 \%$ and $25.9 \%$ lower than the $\mathrm{C}_{\mathrm{Lmax}}$ found in membrane wing. Based on this result, it shows that the washout morphing motion induced on each TM wing has not only reduced the lift generation on the wing but also the $\mathrm{C}_{\mathrm{Lmax}}$. Larger morphing motion induced by higher morphing force has reduced the $\mathrm{C}_{\mathrm{Lmax}}$ magnitude on the wing.

$\mathrm{C}_{\mathrm{L}}$ curve for each wing increases proportionally with AoA until it reaches its maximum value at stall angle $\left(\alpha_{\text {stall }}\right)$. Based on the $\alpha_{\text {stall }}$ analysis, surprisingly the results show that each wing has almost identical $\alpha_{\text {stall }}$ magnitude at approximately $\alpha_{\text {stall }}=31^{\circ}$. The percentage difference between the wings is below than $2 \%$. Based on the results, it shows that the morphing motion on the TM wing does not affect the overall $\alpha_{\text {stall }}$ performance on the wing. However, it may affect the overall flight envelope for the MAV wing. The flight envelope performance (i.e. $\alpha_{\text {stall }}-\alpha_{\mathrm{CL}=0}$ ) for each wing can be determined based on the AoA range between the zero-lift angle $\left(\alpha_{\mathrm{CL}=0}\right)$ and $\alpha_{\text {stall }}$

Analysis on $\alpha_{\mathrm{CL}=0}$ has been conducted for each wing at AoA between $-10^{\circ}$ to $10^{\circ}$. The results show that membrane wing produces the earliest $\alpha_{\mathrm{CL}=0}$ magnitude at $-4.4^{\circ}$. In contrast, the TM5N wing exhibits the most delayed $\alpha_{\mathrm{CL}=0}$ magnitude at $5.2^{\circ}$, about $9.7^{\circ}$ delayed from the membrane wing. The TM1N and TM3N wing produce $\alpha_{\mathrm{CL}=0}$ at $-2.1^{\circ}$ and $\alpha_{\mathrm{CL}=0}=2.5^{\circ}$, respectively. It is learned that TM1N and TM3N wings have delayed $\alpha_{\mathrm{CL}=0}$ magnitude about $2.4^{\circ}$ and $6.9^{\circ}$ compared to the membrane wing, respectively. Based on the $\alpha_{\mathrm{CL}=0}$ analysis, it shows that the membrane wing produces the largest flight range $\left(\alpha_{\text {stall }}-\alpha_{\mathrm{CL}=0}\right)$ at $35.4^{\circ}$. This is followed by the TM1N and TM3N wings at $\alpha_{\text {stall }}-\alpha_{\mathrm{CL}=0}=33.4^{\circ}$ and $28.5^{\circ}$, respectively. However, TM5N has the least flight range at $\alpha_{\text {stall }}-\alpha_{\mathrm{CL}=0}=$ $25.8^{\circ}$. Based on these results, one can conclude that larger morphing force produces a delayed $\alpha_{\mathrm{CL}=0}$ magnitude, which in turn has reduced the flight envelope for the MAV wing. The camber deformation due to the morphing actuation has abruptly changed the wing camber, which consequently reduces the AoA flight range and thus the overall MAV flight envelope.

Based on lift distribution results, one can conclude that the washout morphing wing technique has produced a malevolent performance on MAV wing, particularly for current wing selection. The morphing motion has altered the overall lift distribution especially for the overall $\mathrm{C}_{\mathrm{L}}, \mathrm{C}_{\mathrm{Lmax}}$ and $\alpha_{\mathrm{CL}=0}$ magnitudes. Each morphing wing has produced lower $\mathrm{C}_{\mathrm{L}}, \mathrm{C}_{\mathrm{Lmax}}$ and $\alpha_{\mathrm{CL}=0}$ value compared to the baseline (membrane) wing. In fact, a higher level of morphing motion found in TM3N and TM5N has worsened the magnitude of $C_{L}, C_{L \max }$ and $\alpha_{C L=0}$ found on the TM MAV wing. As a result, the flight range found in those TM wings has significantly reduced by at least $6 \%$ compared to the baseline (membrane) wing. Despite the degradation found in overall $\mathrm{C}_{\mathrm{L}}, \mathrm{C}_{\mathrm{Lmax}}$ and $\alpha_{\mathrm{CL}=0}$ magnitudes, TM wing is able to maintain the $\alpha_{\text {stall }}$ value found on each wing. The difference in $\alpha_{\text {stall }}$ value between the baseline and TM wings is below than $2 \%$. By maintaining a high $\alpha_{\text {stall }}$ value with lower $C_{L}$ and $C_{L m a x}$ magnitudes, TM wing can offer more agility for MAV manoeuvrability. This condition might be useful during an indoor mission or obstacle avoidance flight.

\section{Conclusion}

In this works, an experimental study on the washout TM wing has been conducted with a view to investigate the lift distribution under the influence of morphing motion. A special test rig has been developed to ensure that the wash out morphing technique can be achieved and is suitable for wind tunnel testing purpose. Based on the wing deformation result, it is clearly shown that the test rig is able to produce a significant amount of wing tip deflection at the morphing point. Morphing force produces the wing tip deflection, which is used to indicate morphing motion. In fact, higher morphing force will induce larger morphing motion. Based on the three levels of morphing (TM1N, TM3N and TM5N), it clearly shows that TM5N induces the largest wing tip deflection and morphing motion. On the other hand, the baseline (membrane) wing has the non-morphing condition.

Based on the lift distribution results, it shows that the morphing motion has significantly affected the overall lift distribution on the MAV wing, especially in the $C_{L}, C_{L \max }$ and $\alpha_{C L=0}$ magnitudes. The results clearly show that the morphing motion has deteriorated the overall $C_{L}, C_{L \max }$ and $\alpha_{C L=0}$ performance of the MAV wing. In fact, the deterioration in $\mathrm{C}_{\mathrm{L}}, \mathrm{C}_{\mathrm{Lmax}}$ and $\alpha_{\mathrm{CL}=0}$ magnitudes are evidently shown at higher morphing levels, especially for TM3N and TM5N wings. Resulting from the lower $\alpha_{\mathrm{CL}=0}$ magnitude, the flight range 
found in those TM wings is significantly reduced by at least $6 \%$ compared to that of the baseline (membrane) wing. Based on the initial structural investigation, the result shows that the TM wing induces a slight downward nose deflection at the front part of the wing, which in turn decreases the local angle of attack magnitude, especially near the wing tip area. Despite the degradation found in the overall $C_{L}, C_{L \max }$ and $\alpha_{C L=0}$ magnitudes, TM wing is able to maintain the $\alpha_{\text {stall }}$ value found on each wing. By maintaining high $\alpha_{\text {stall }}$ value with lower $C_{L \text { and }} C_{L \max }$ magnitude, TM wing can offer more agility for MAV manoeuvrability that will be useful for an indoor mission or obstacle avoidance flight. In future works, a detailed study on the vortices formation surrounding the TM wing will be conducted to further elucidate the influence of the washout morphing wing on the lift distribution results.

\section{Acknowledgement}

The authors acknowledge the technical and financial support from Universiti Teknologi MARA Cawangan Pulau Pinang and also the Government of Malaysia for this study.

\section{References}

[1] Ismail NI, Zulkifli AH, Abdullah MZ, Basri MH \& Abdullah NS (2013), Computational aerodynamic analysis on perimeter reinforced (PR)-compliant wing. Chinese Journal of Aeronautics 26(5), 1093-1105

[2] Madangopal R, Khan Z \& Agrawal SK (2005), Biologically inspired design of small flapping wing air vehicles using four-bar mechanisms and quasi-steady aerodynamics. Journal of Mechanical Design 127(4), 809

[3] Ismail NI, Zulkifli AH, Abdullah MZ, Basri MH \& Abdullah NS (2014), Optimization of aerodynamic efficiency for twist morphing MAV wing. Chinese Journal of Aeronautics 27(3), 475-487

[4] Ratti J \& Vachtsevanos G (2011), Inventing a biologically inspired, energy efficient micro aerial vehicle. Journal of Intelligent \& Robotic Systems 65, 437-455

[5] Thill C, Etches J, Bond I, Potter K \& Weaver P (2008), Morphing skins. The Aeronautical Journal 112(1129), 117-139

[6] Ismail NI, Zulkifli AH, Basri MH, Talib RJ \& Yusoff H (2015), Lift performance of a twist morphing MAV wing. Jurnal Teknologi 75(8), 31-35

[7] Di Luca M, Mintchev S, Heitz G, Noca F \& Floreano D (2017), Bioinspired morphing wings for extended flight envelope and roll control of small drones. Interface Focus 7(1), 20160092

[8] Ursache NM (2006), The design of adaptive structures for wing morphing. PhD Thesis Dissertation, University Of Southampton

[9] Ahmed RI, Talib ARA, Rafie ASM \& Djojodihardjo H (2017), Aerodynamics and flight mechanics of MAV based on Coanda effect. Aerospace Science and Technology 62, 136-147

[10] Ismail NI (2014), Aerodynamic performances and flow structure investigations on active twist morphing MAV wing. Universiti Teknologi MARA 